\title{
Corrigendum
}

\section{Corrigendum to "Chicken Collagen from Law Market Value By-Products as an Alternate Source"}

\author{
Kumudini A. Munasinghe, ${ }^{1,2}$ Jurgen G. Schwarz, ${ }^{2}$ and Anthony K. Nyame ${ }^{3}$ \\ ${ }^{1}$ Department of Biological Sciences, Salisbury University, Salisbury, MD 21801, USA \\ ${ }^{2}$ Food Science and Technology Ph. D. Program, Department of Agriculture, Food and Resource Sciences, \\ University of Maryland Eastern Shore, Princess Anne, MD 21853, USA \\ ${ }^{3}$ Department of Natural Sciences, University of Maryland Eastern Shore, Princess Anne, MD 21853, USA
}

Correspondence should be addressed to Kumudini A. Munasinghe; kamunasinghe@salisbury.edu

Received 20 January 2015; Accepted 15 February 2015

Copyright (C) 2015 Kumudini A. Munasinghe et al. This is an open access article distributed under the Creative Commons Attribution License, which permits unrestricted use, distribution, and reproduction in any medium, provided the original work is properly cited.

The title of the paper "Chicken Collagen from Law Market Value By-Products as an Alternate Source" is wrong and should read "Chicken Collagen from Low Market Value ByProducts as an Alternate Source." 

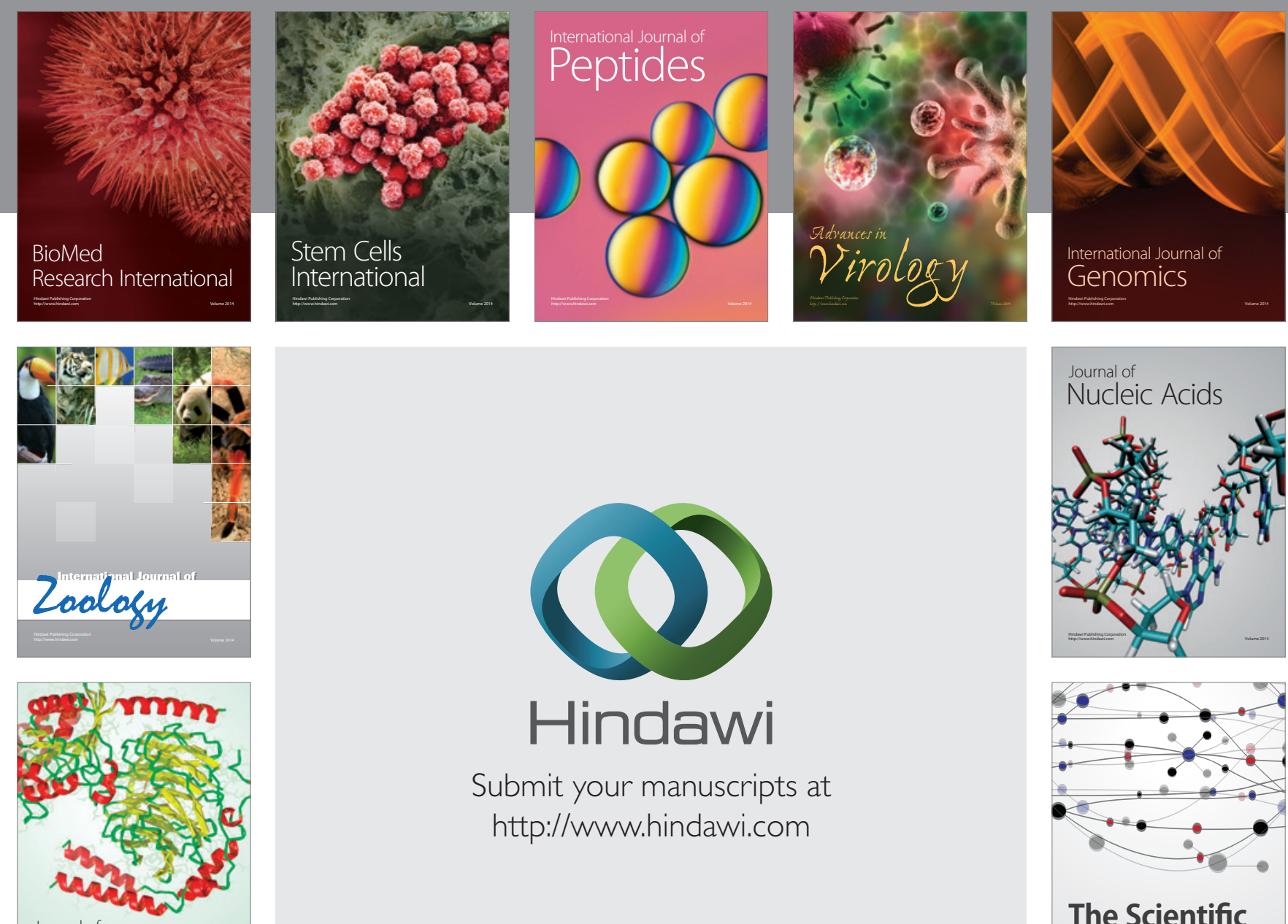

Submit your manuscripts at

http://www.hindawi.com

Journal of
Signal Transduction
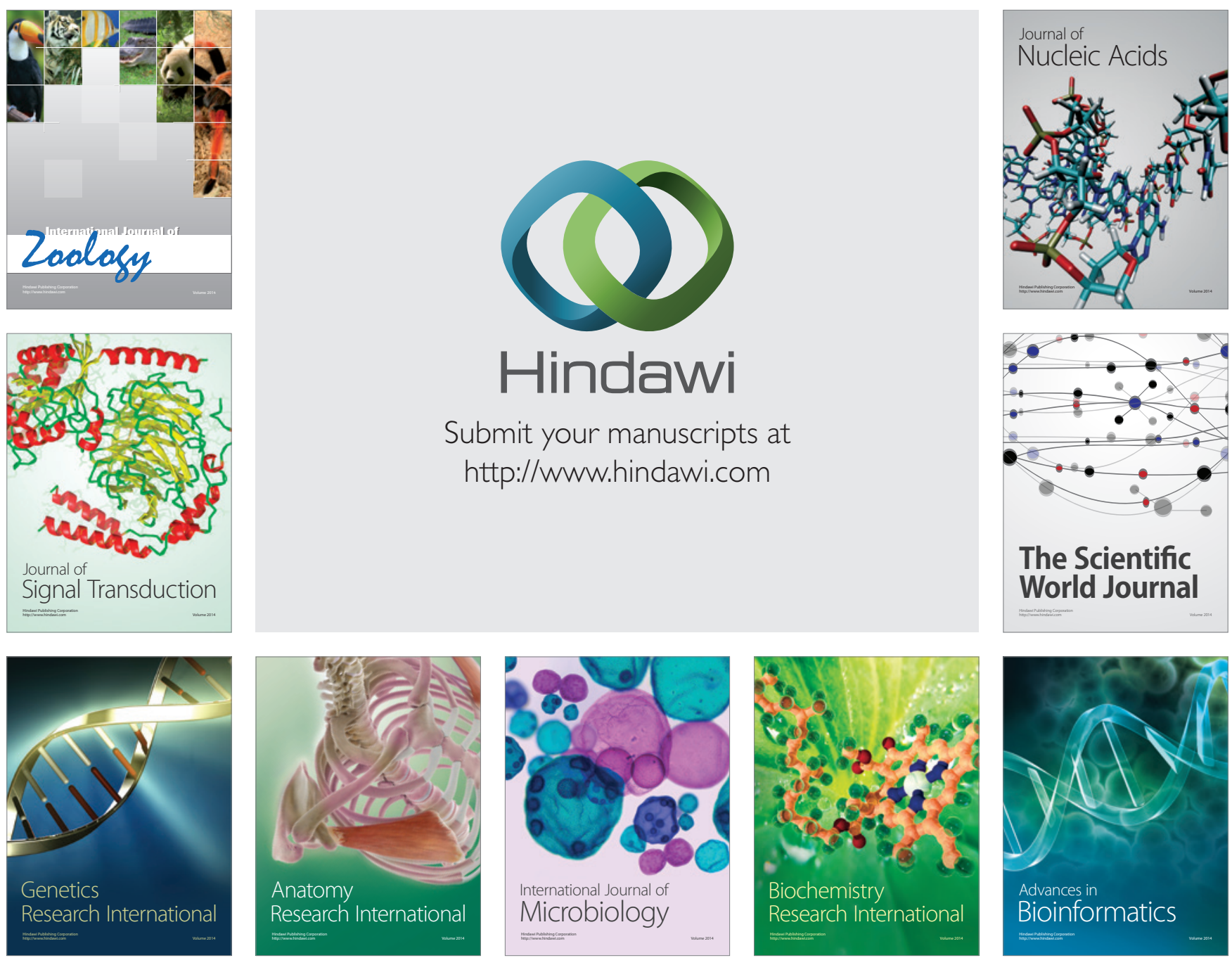

The Scientific World Journal
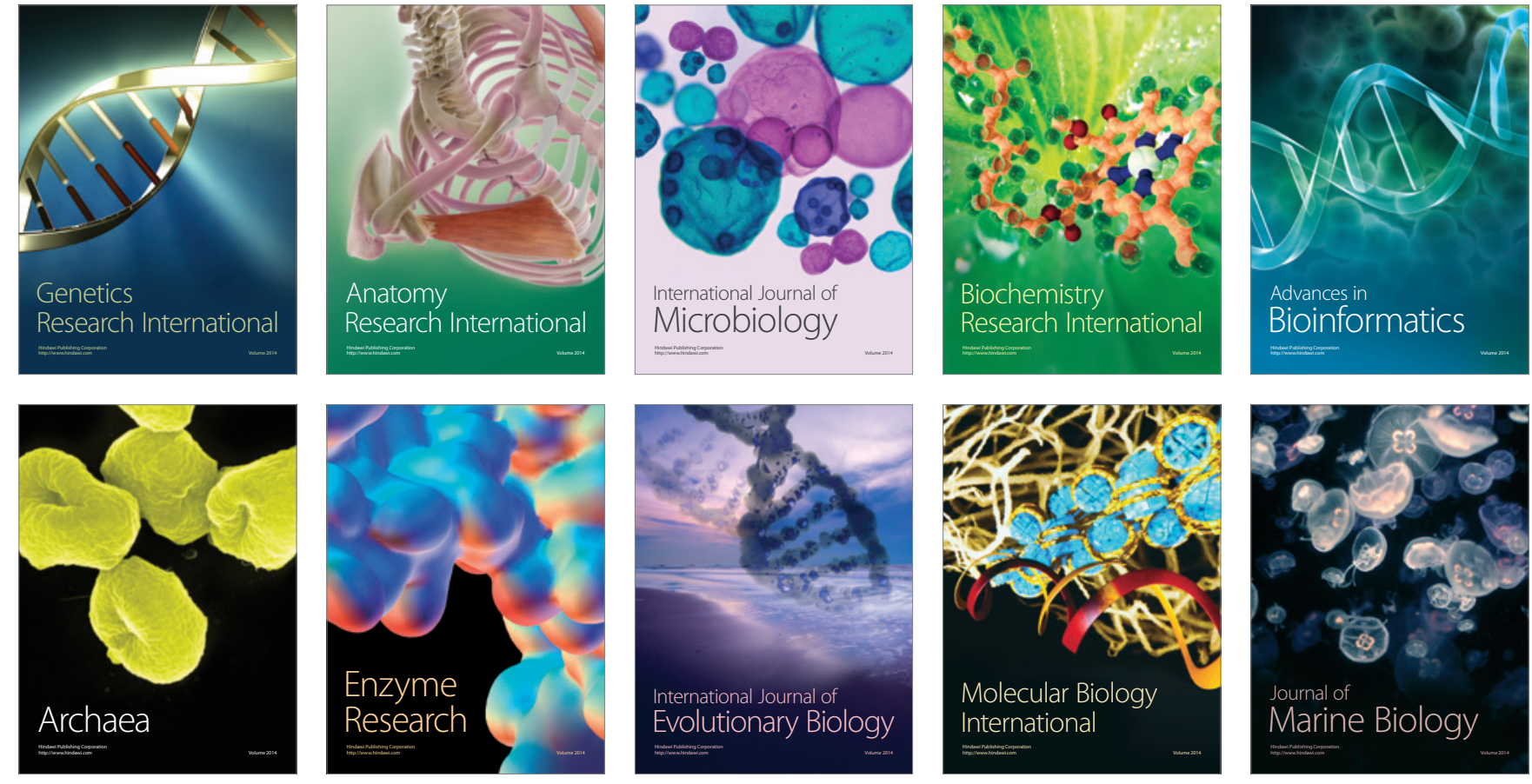